\title{
Setting Behavior and Drug Release from Brushite Bone Cement prepared with Granulated Hydroxyapatite and $\beta$-Tricalcium Phosphate
}

\author{
Yeong-Jun Son, In-Cheol Lee, Hyun-Ho Jo, Tai-Joo Chung, and Kyung-Sik $\mathbf{O h}^{\dagger}$ \\ School of Advanced Materials Engineering, The Center of Biomedical Materials and Biotechnology, \\ Andong National University, Andong 36729, Korea
}

(Received October 3, 2018; Accepted December 10, 2018)

\begin{abstract}
Calcium phosphate bone cement was prepared to contain antibiotics for release after setting using granulated $\beta$-tricalcium phosphate ( $\beta$-TCP) and hydroxyapatite (HA). Gentamicin sulfate (GS) solution was infiltrated within the interconnected pores of the granule to avoid affecting the setting reaction and for protection of GS during the setting. Consequently, the setting time and the temperature increase were not affected, regardless of the loading of GS. The release of the GS from the cement was estimated by measuring the concentration at regular intervals from the cement dipped solution. The $\beta$-TCP granule loaded with GS exhibited the saturation of accumulative concentration at $16 \mathrm{~h}$. In contrast, the HA granule with GS exhibited steady increase in accumulative concentration of over $10 \mu \mathrm{g} / \mathrm{ml}$ at $144 \mathrm{~h}$. Thus, the granulated cement could release the GS greater than the minimum inhibitory concentration of staphylococcus during the prescription peroid of the oral antibiotics.
\end{abstract}

Key words : Bone cement, Granule, Gentamicin, Hydroxyapatite, $\beta$-TCP

\section{Introduction}

C alcium phosphate bone cement is used for filling bony defects in orthopaedic surgery. ${ }^{1)}$ As liquid setting agent is utilized with the hydration of calcium phosphates powder during the setting of cement, the pores remain intact after setting. By filling the pores with a drug, the bone cements can release the antibiotics. ${ }^{2}$ As inflammation is strongly anticipated after orthopaedic surgery, an oral dose of antibiotics is prescribed for patients. Bone cement with antibiotic can reduce the amount of oral dose administered after orthopaedic surgery. Since long term treatment is usually necessary for bone diseases such as osteomyelitis due to the poor accessibility to the infection site, ${ }^{3)}$ the use of calcium phosphate block with antibiotics was proposed to enhance the curative effect and reduce the oral dose required. ${ }^{4)}$

As a vehicle, $\beta$-tricalcium phosphate $\left(\mathrm{Ca}_{3}\left(\mathrm{PO}_{4}\right)_{2}: \beta\right.$-TCP $)$ based cement is more advantageous than polymethylmethacrylate (PMMA) due to its resorbability ${ }^{5)}$ and osteoconductivity. In addition, unlike PMMA cement, $\beta$-TCP based cement does not need to be surgically removed from the infection site. ${ }^{6)}$ According to previous reports, ${ }^{2,7)}$ gentamicin sulfate (GS) can be incorporated within cement as an antibiotic. The GS was dissolved in the setting agent and mixed with the powder for setting. ${ }^{2)}$ The release of GS was concentrated at the initial moment and the properties of cement such as setting time changed considerably due to the sulfate

\footnotetext{
Corresponding author : Kyung Sik Oh

E-mail : ksoh@anu.ac.kr

Tel : +82-54-820-5783 Fax : +82-54-820-6211
}

ions released from GS. ${ }^{2)}$ Efforts have been made to prolong the release of GS by adding poly acrylic acid (PAA) to the cement. ${ }^{7)}$ As a result of binding between PAA and GS, the decomposition and subsequent release were delayed. However, with the introduction of PAA, the properties of cement were inevitably altered.

In the development of drug releasing bone cement, the several requirements needs to be considered. First, the sufficient amount of antibiotics should be loaded within the cement. The minimum inhibitory concentration (MIC) should be reached by the release of the antibiotic. Second, the release of the antibiotics should continue for a sufficient period of time. The release period can be established by referring the oral dose administration period ${ }^{3)}$ of the surgical patient. Third, after loading the antibiotics, the cement needs to maintain similar setting properties to those prior to loading. If the setting properties considerably differ, surgeons are usually hesitant to substitute the drug loaded cement. Lastly, excessive temperature increase during the setting should be avoided. ${ }^{8)}$ The degradation of loaded antibiotics is anticipated, if the drug is thermosensitive.

In this work, calcium phosphate granules were prepared and extensively used to meet the above requirements. As starting components of cement, $\beta$-TCP and monocalcium phosphate monohydrate $\left(\mathrm{Ca}\left(\mathrm{H}_{2} \mathrm{PO}_{4}\right)_{2} \mathrm{H}_{2} \mathrm{O}\right.$ : MCPM) were mixed to form dicalcium phosphate dihydrate $\left(\mathrm{CaHPO}_{4} \cdot 2 \mathrm{H}_{2} \mathrm{O}\right.$ : DCPD), which has the mineral name of brushite. ${ }^{9)}$ The properties of cement such as setting time and temperature increase are strongly affected by the rate of the settng reaction, which is dependent on the activity of the starting powder. The fine powder leads to a fast setting reaction due to 
its reactivity. On the contrary, coarse granulated powder results in an extended setting. The granulated powder was tested as a starting material in a number of reports. ${ }^{8,10-12)}$ To enhance the effect of the extension, the granules were heated at over $1000^{\circ} \mathrm{C}$ to further reduce the chemical activity. The resultant granules formed a highly dense structure with a very small specific surface area. The reduction of the surface area decreased the required volume of the setting agent and resulted in an increase in the density and strength $^{11)}$ of the cement. The dense $\beta$-TCP granule was also effective in reducing the temperature increase ${ }^{8)}$ and in controlling the shelf-life. ${ }^{13)}$

The kinetics of reaction can also be manipulated by the introduction of a more chemically stable compound of similar composition such as Hydroxyapatite (HA) instead of $\beta$ TCP. As HA is much less soluble than $\beta$-TCP, ${ }^{14)}$ its introduction can prolong the setting time and reduce the temperature rise. In this work, both $\beta$-TCP and HA were prepared to form granules with a dense surface and porous inner structure for the loading of antibiotics.

During the setting, the granules are decomposed from the surface. However, antibiotics preserved within the granule are less likely to participate in the setting reaction. Therefore, the antibiotics may not affect the kinetics of the setting reaction and the release is extended until the complete disintegration of the granules. As HA granules are less reactive than $\beta$-TCP granules, the release of antibiotics may be prolonged further.

In this work, dense $\beta$-TCP and HA granules were introduced for slow decomposition and innermost incorporation of the drug. The $\beta$-TCP and HA granules were prepared by spray-drying and subsequent heat-treatment. The setting properties of the cement were evaluated for GS loaded cement and compared with those of GS free cement.

\section{Experimental Procedure}

\subsection{Preparation of granules with GS}

Based on the previous reports, ${ }^{11,15)}$ the suspensions of HA (Sigma-Aldrich, Japan 95\%) and $\beta$-TCP (Sigma-Aldrich, Germany, 96\%) with the solid loading of 10 and 35 vol\%, respectively, were prepared. HA and $\beta$-TCP granules were spray-dried and subsequently heat-treated at $1000 \sim$ $1250^{\circ} \mathrm{C}$ for $2 \mathrm{~h}$. The cross-sections of the HA and $\beta$-TCP granules were exposed by lapping the granules fixed in the resin. After polishing with $1 \mu \mathrm{m}$ diamond paste, the inner structure of the granules was observed by scanning electron microscopy (SEM, Tescan VEGA II LMU). The contact angles of GS solution (Yantai Justaware Pharmaceutical Co. Ltd.) were observed on the polished surfaces of the dense HA and $\beta$-TCP discs in order to find the successful condition of infiltration within the pores of the granules via capillary pressure. The dense discs of HA and $\beta$-TCP, which simulated the surfaces of granules, were prepared by heattreating the uniaxially pressed powder compacts at $1200^{\circ} \mathrm{C}$ for $2 \mathrm{~h}$. The concentrations of GS solution were varied between $0.1 \mathrm{~g} / \mathrm{ml}$ and $0.5 \mathrm{~g} / \mathrm{ml}$. After dipping the HA or $\beta$ TCP granules in the GS solution for $1 \mathrm{~h}$ and subsequent drying at $150^{\circ} \mathrm{C}$ for 3 days, the amount of infiltrated GS was determined by thermogravimetric (TG) analysis. During the TG analysis, the granules with GS were heated at a rate of $10^{\circ} \mathrm{C} / \mathrm{min}$ to $500^{\circ} \mathrm{C}$ (TG8120, Rigaku, TX, US).

\subsection{Preparation of cement with granules}

A cement specimen was composed of powder $(1 \mathrm{~g})$ and from 0.6 to $1.0 \mathrm{ml}$ of setting agent. The powder consisted of $0.4 \mathrm{~g}$ of monocalcium phosphate monohydrate $\left(\mathrm{Ca}\left(\mathrm{H}_{2} \mathrm{PO}_{4}\right)_{2} \cdot \mathrm{H}_{2} \mathrm{O}\right.$ : MCPM, Sigma-Aldrich, Japan, 95\%) and $0.6 \mathrm{~g}$ of $\beta$-TCP or HA. As MCPM is a phosphor rich $(\mathrm{Ca} / \mathrm{P}=1)$ calcium phosphate compound, it dissolves and emits phosphoric acid and subsequently reacts with calcium rich $(\mathrm{Ca} / \mathrm{P}>1.5)$ compound such as $\beta$-TCP and HA. In this work, three groups were prepared depending on the combination calcium rich compounds. The first group, designated as T6, was entirely composed of $\beta$-TCP granules. The second group, designated as H2T4, cosisted of $0.2 \mathrm{~g}$ of HA granules and $0.4 \mathrm{~g}$ of $\beta$-TCP powder. In the third group, designated as $\mathrm{H} 4 \mathrm{~T} 2$, the amount of HA granules increased to $0.4 \mathrm{~g}$, while the $\beta$-TCP powder was reduced to $0.2 \mathrm{~g}$.

\subsection{Characterization of cement}

After kneading the powder and the setting agent for $30 \mathrm{~s}$, the paste was placed in a Teflon mold to prepare a cubic specimen with a $1 \mathrm{~cm}$ edge. The setting time of the paste was estimated using a Vicat needle and the change of temperature during the setting was measured by a thermocouple embedded in the paste. After setting, the phase of the end product was analyzed using X-ray diffraction (D/MAX2000, Rigaku, TX, US).

\subsection{Release of GS}

Three specimens were selected to compare the release of GS. The first specimen was prepared by dissolving GS in the setting agent and was thus named as 'GS in setting agent'. The second specimen was prepared from the $\beta$-TCP granules loaded with GS (T6), and was thus named 'GS in $\beta$ TCP granule'. The third specimen was prepared from H4T2 and was thus named 'GS in HA granule'. After demolding the cubic cement specimen with an edge of $1 \mathrm{~cm}$, the specimen was dipped in $250 \mathrm{ml}$ of deionized (DI) water and maintained at $37^{\circ} \mathrm{C}$. The solution with cement was constantly stirred to ensure the homogeneous distribution of the released GS. $1 \mathrm{ml}$ of aliquot was taken after $10 \mathrm{~m}, 30 \mathrm{~m}, 1 \mathrm{~h}$, $2 \mathrm{~h}, 4 \mathrm{~h}, 12 \mathrm{~h}, 24 \mathrm{~h}, 48 \mathrm{~h}$, and $144 \mathrm{~h}$. The concentration of GS was measured using an ultraviolet spectrophotometer (Cary-5000, CA, US).

\section{Results}

\section{1. $\beta$-TCP and HA granule}

Round granules were obtained by spray-drying the $\beta$-TCP suspension (Fig. 1(a)). The average diameter was measured 


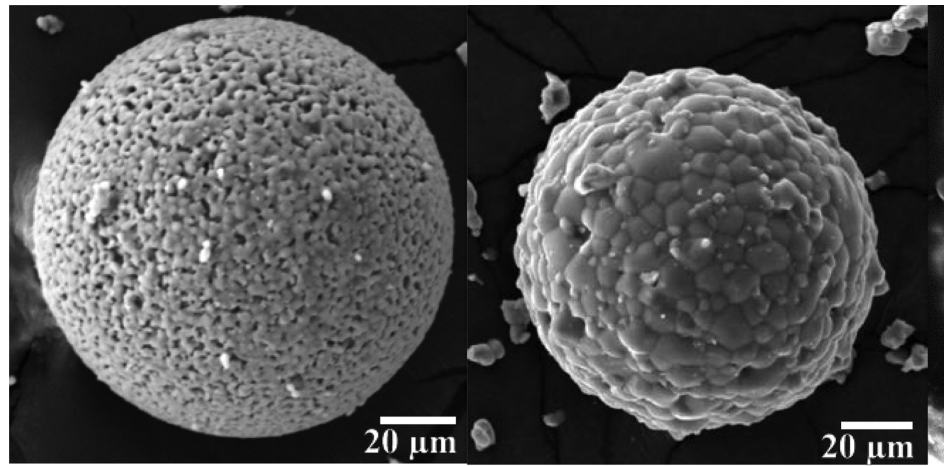

(a) (b)

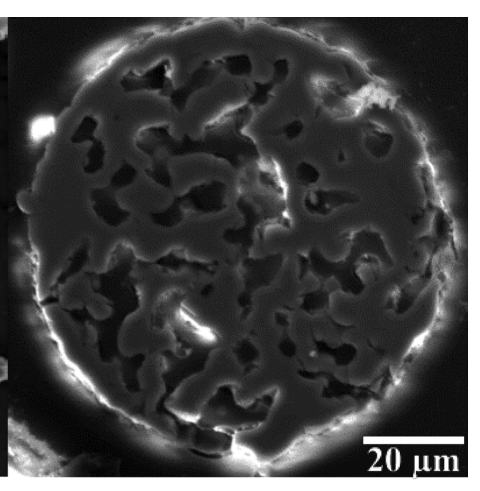

(c)

Fig. 1. Morphologies of $\beta$-TCP granule (a) as received and (b) heat treated at $1150^{\circ} \mathrm{C}$ for $2 \mathrm{~h}$. Cross-section (c) of $\beta$-TCP granule heat treated at $1150^{\circ} \mathrm{C}$ for $2 \mathrm{~h}$.

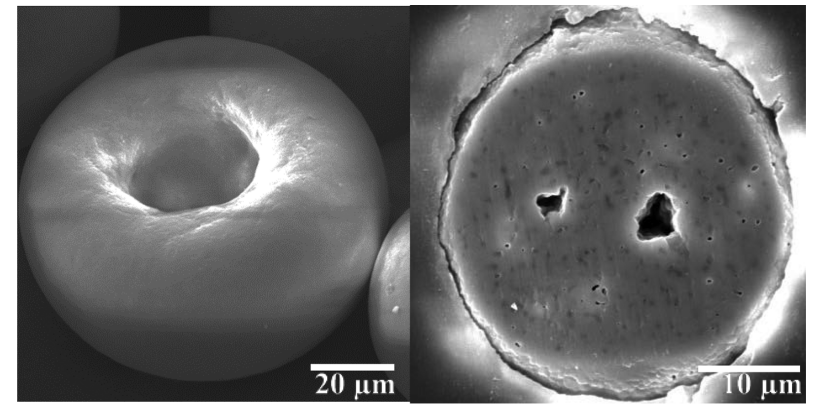

(a)

(b)

Fig. 2. Morphologies (a) and cross section (b) of HA granule heat treated at $1150^{\circ} \mathrm{C}$ for $2 \mathrm{~h}$.

to be $144 \mu \mathrm{m}$. Heat-treatment at $1150^{\circ} \mathrm{C}$ led to the densification of granules along with the coarsening of grains (Fig. 1(b)). Observation of the cross section (Fig. 1(c)) revealed the coarsening of pores with the heat-treatment. As shown in Fig. 1(c), the pores were interconnected with each other and open on the surface. At $1150^{\circ} \mathrm{C}$, the porosity was estimated as $21 \%$ from the cross-section image analysis.

Unlike the $\beta$-TCP granules, the spray-dried HA granules had dimples, as shown in Fig. 2(a). Dimples are known to form due to the abrupt evaporation of solvent during spraydrying. ${ }^{16)}$ As a result of heat-treatment at $1150^{\circ} \mathrm{C}$, the average diameter of the granules was $62.4 \mu \mathrm{m}$. The HA granules were smaller than the $\beta$-TCP granules due to low solid loading of the suspension. The cross-section of the HA granules showed the existence of inner voids, which can accomodate the drug (Fig. 2(b)).

\subsection{Introduction of GS solution to the granules}

The pores within the granules shown in Figs. 1 and 2 can contain liquid antibiotics by capillary pressure. As the magnitude of the capillary pressure is dependent on the contact angle between the GS solution and solid surface of the granules, conditions need to be found that enable small contact angles. The contact angles were observed on the flat polished surface of $\beta$-TCP and HA. Fig. 3 shows the GS solution applied on the surface of the $\beta$-TCP disc. The

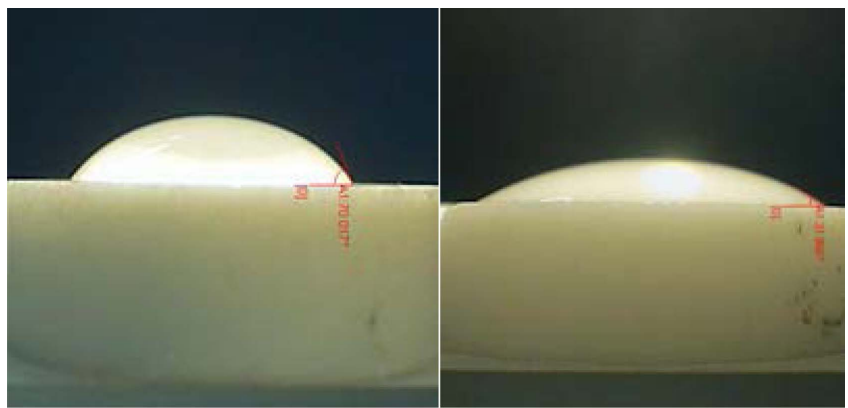

(a)

(b)

Fig. 3. Contact angles of GS solution at concentrations of (a) $0.01 \mathrm{~g} / \mathrm{ml}$ and (b) $0.05 \mathrm{~g} / \mathrm{ml}$ on the surface of polished $\beta$-TCP disc.

contact angle varied depending on the concentration of GS solution. At $0.01 \mathrm{~g} / \mathrm{ml}$, the contact angle was $70.0^{\circ}$, but it decreased to $31.6^{\circ}$ at $0.05 \mathrm{~g} / \mathrm{ml}$. Fig. 4 shows the GS solution placed on the surface of the HA disc. The contact angles were $42^{\circ}$ and $59^{\circ}$ at the concentrations of 0.01 and $0.05 \mathrm{~g} / \mathrm{ml}$, respectively. Therefore, irrespective of the types of granules and concentrations, successful absorption of GS was expected

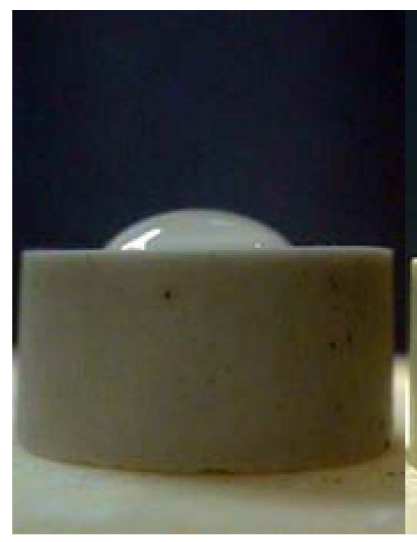

(a)

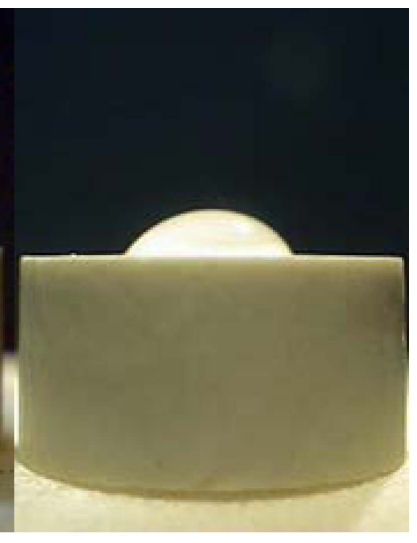

(b)
Fig. 4. Contact anlges of GS solution at concentrations of (a) $0.01 \mathrm{~g} / \mathrm{ml}$ and (b) $0.05 \mathrm{~g} / \mathrm{ml}$ on the surface of polished HA. 
(a)
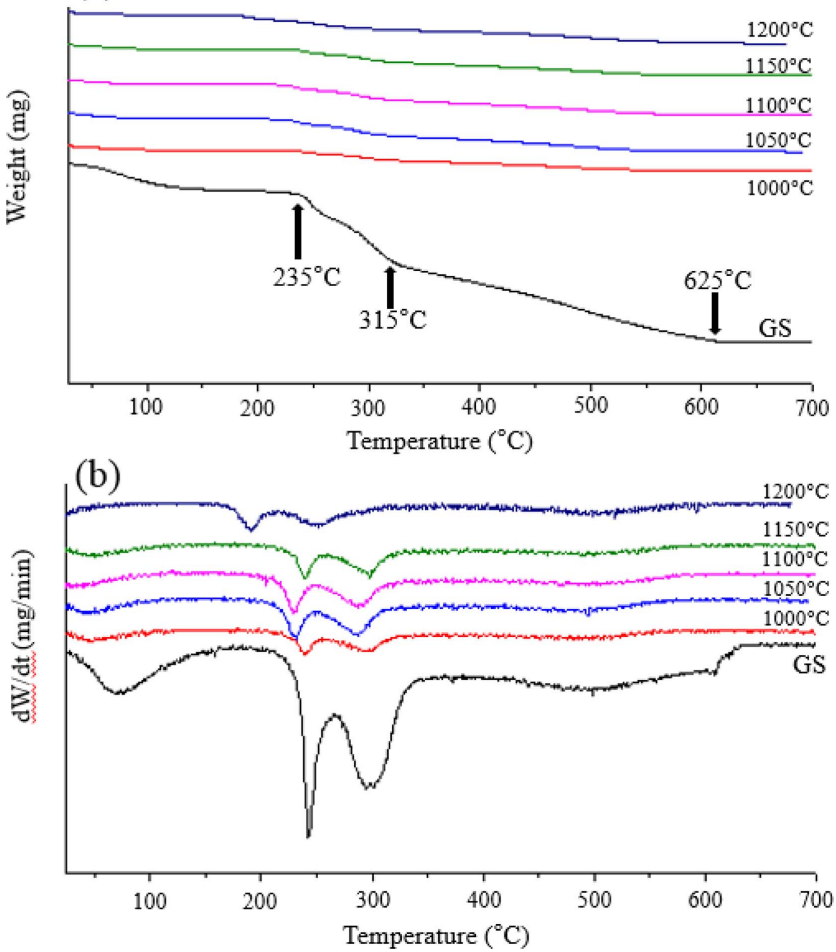

Fig. 5. Change of mass with temperature (a) and derivative with time (b) in GS loaded $\beta$-TCP.

because the contact angles were considerably smaller than $60^{\circ}$.

The sufficiently small contact angles enabled loading of $0.05 \mathrm{~g} / \mathrm{ml}$ GS solution in the granules. The TG analysis given in Fig. 5 showed the change of mass with temperature for pure GS and the GS loaded B-TCP granules, depending on the heat-treatment temperature of granules before loading. In Fig. 5(a), abrupt changes of mass are observed at 235,315 , and $625^{\circ} \mathrm{C}$ which are expressed as peaks in the derivative plot in Fig. 5(b). The positions of peaks coincide between pure GS and the granules loaded with GS. Therefore,
Table 1. Amount of GS in the $\beta$-TCP Granules with Respect to the Heat Treatment Temperature

\begin{tabular}{ccc}
\hline $\begin{array}{c}\text { Heat Treatment } \\
\text { Temperature }\left({ }^{\circ} \mathrm{C}\right)\end{array}$ & $\begin{array}{c}\text { Reduced mass } \\
(\%)\end{array}$ & $\begin{array}{c}\text { Drug loaded } \\
(\mathrm{ml} / \mathrm{g})\end{array}$ \\
\hline 1050 & 3.29 & 0.65 \\
1100 & 2.75 & 0.55 \\
1150 & 2.33 & 0.47 \\
1200 & 2.34 & 0.47 \\
\hline
\end{tabular}

Table 2. Amount of GS in the HA Granules with Respect to the Heat Treatment Temperature

\begin{tabular}{ccc}
\hline $\begin{array}{c}\text { Heat Treatment } \\
\text { Temperature }\left({ }^{\circ} \mathrm{C}\right)\end{array}$ & $\begin{array}{c}\text { Reduced mass } \\
(\%)\end{array}$ & $\begin{array}{c}\text { Drug loaded } \\
(\mathrm{ml} / \mathrm{g})\end{array}$ \\
\hline 1000 & 3.93 & 0.78 \\
1100 & 4.47 & 0.89 \\
1150 & 5.01 & 1.00 \\
1200 & 3.33 & 0.67 \\
\hline
\end{tabular}

the successful infiltration of GS in the heat treated granules could be verified from Fig. 5 .

The amount of loaded GS was calculated from the loss of mass shown in Fig. 5(a). By dividing the loss of mass in granules with the loss of mass of pure GS, the fractions of GS in the granules were calculated according to the heattreatment temperature, as shown in Tables 1 and 2 for both $\beta$-TCP and HA. The weight of GS in the granule in Table 1 and 2 was converted to the volume of GS per one gram of granules, considering the specific volume $(50 \mathrm{mg} / \mathrm{ml})$ of GS at saturated state. ${ }^{17)}$ Therefore, the pores in the granules could successfully accommodate the GS solution, and the volume of GS was expressed per gram of granules as shown in Tables 1 and 2 .

\subsection{Setting properties of cement using granules loaded with GS}

The setting times were observed for the T6 series specimens according to the heat-treatment temperature of the gran-

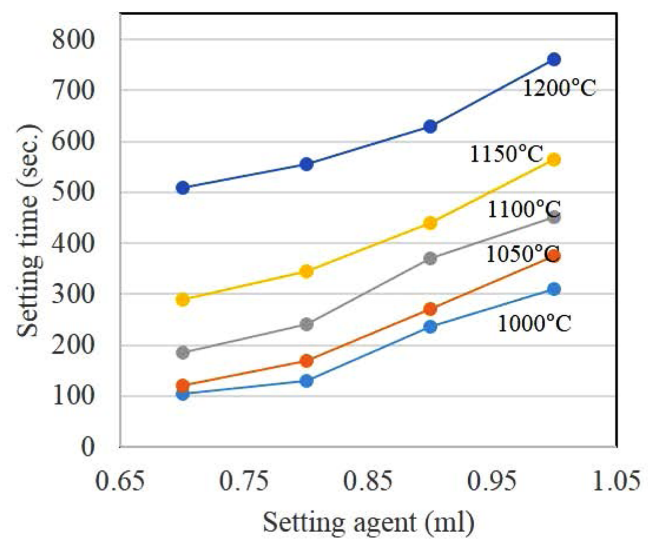

(a)

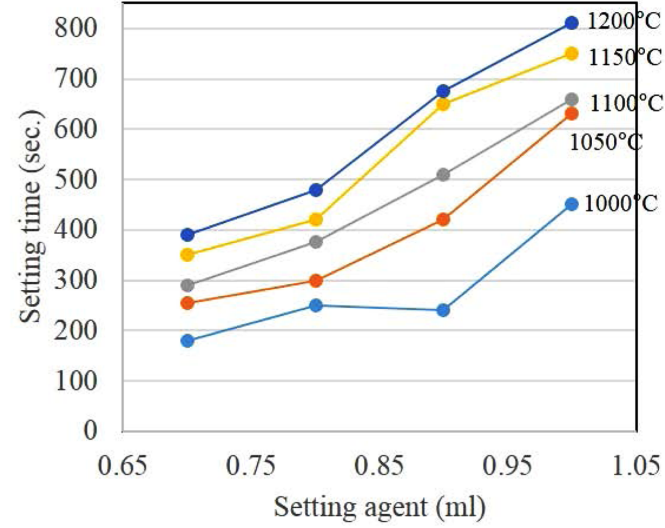

(b)

Fig. 6. Changes of setting time with the amount of setting agent and heat treatment temperature of (a) Gentamicin free and (b) Gentamicin loaded $\beta$-TCP granules. 
ules and the volume of the setting agent. With an increase in the volume of setting agent from 0.7 to $1.0 \mathrm{ml}$ per gram of cement, the setting time of the cement with the $\beta$-TCP granules heated at $1000^{\circ} \mathrm{C}$ increased from $105 \mathrm{sec}$ and $310 \mathrm{sec}$. The setting time of the cement with the $\beta$-TCP granules heated at $1200^{\circ} \mathrm{C}$ also increased with the amount of setting agent from $510 \mathrm{sec}$ to $760 \mathrm{sec}$ for the setting agents of 0.7 and $1.0 \mathrm{ml}$, respectively (Fig. 6(a)). The prolonged setting time was attributed to the reduced reactivity of granules due to the heat-treatment at $1200^{\circ} \mathrm{C}$.

Figure 6(b) shows a change of setting times for the cement containing the GS loaded $\beta$-TCP granules with the amount of setting agent and heat treatment temperatures. The setting time increased from $180 \mathrm{sec}$ and $450 \mathrm{sec}$ with an increase in setting agent from 0.7 to $1.0 \mathrm{ml}$ for the $\beta$-TCP granules heat-treated at $1000^{\circ} \mathrm{C}$. The $\beta$-TCP granules heat treated at $1200^{\circ} \mathrm{C}$ showed setting times of $390 \mathrm{sec}$ to $810 \mathrm{sec}$ for 0.7 and $1.0 \mathrm{ml}$, respectively. A comparison between Figs.

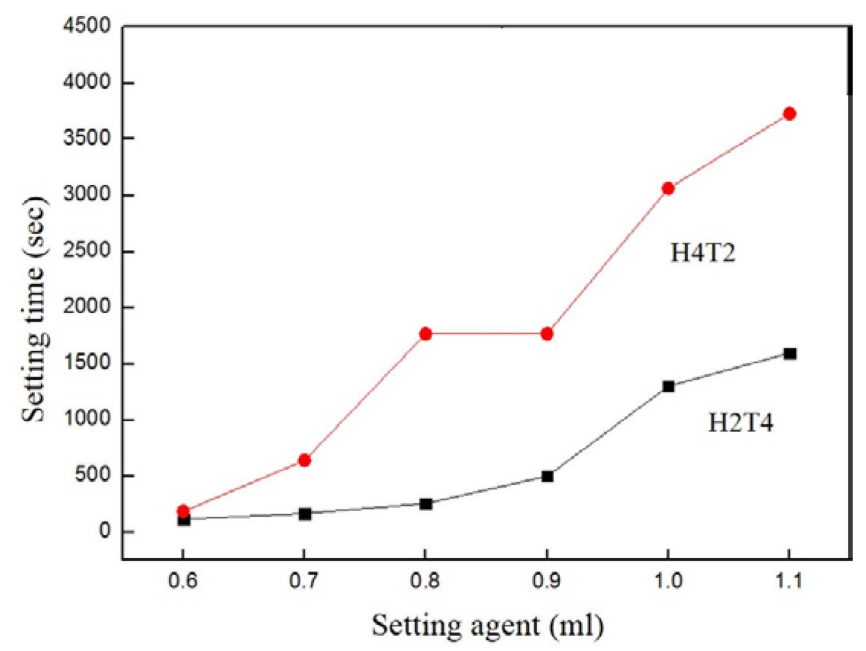

Fig. 7. Changes of setting times in $\mathrm{H} 2 \mathrm{~T} 4$ and $\mathrm{H} 4 \mathrm{~T} 2$ with respect to the volume of the setting agent.

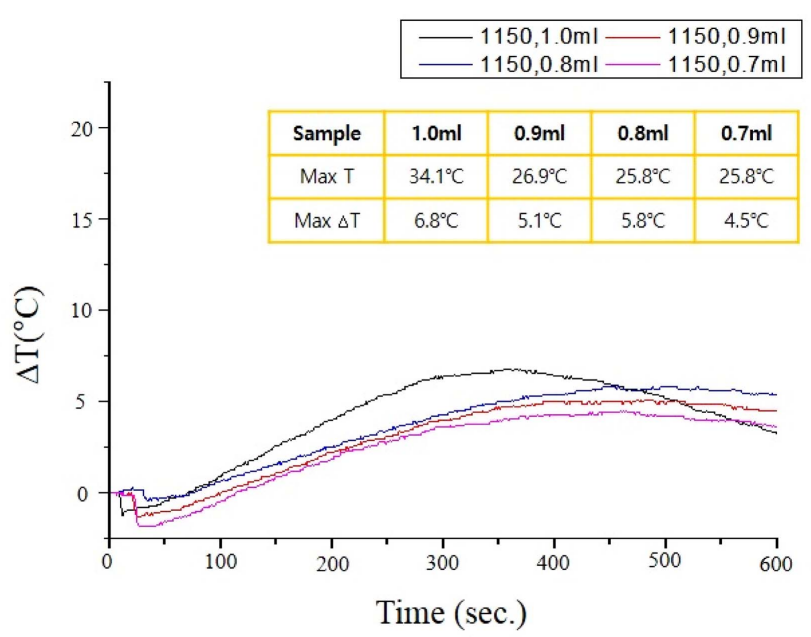

(a)

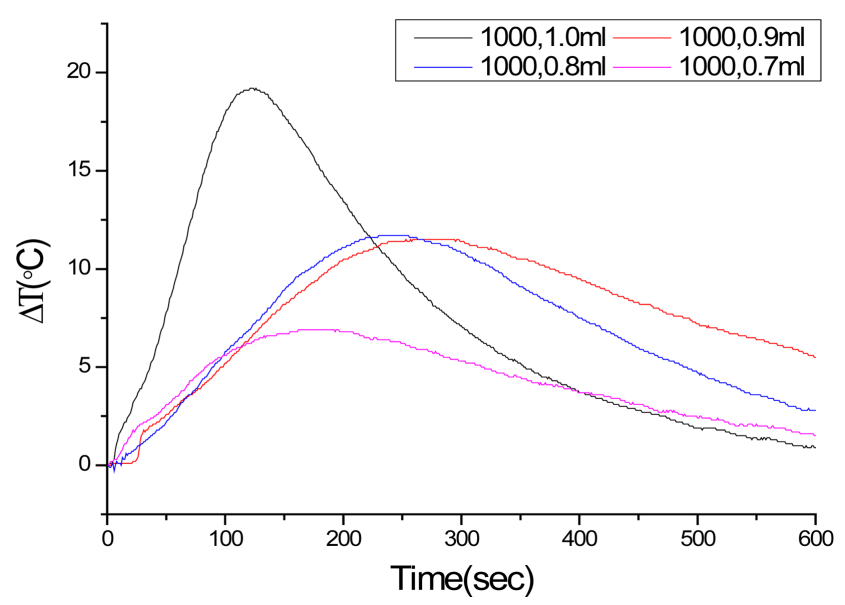

Fig. 8. Temperature increase during setting of cement with respect to the amount of setting agent.

6(a) and 6(b) shows that the changes of setting time with increase in setting agents between GS free and GS loaded cement are very similar. In addition, the absolute values of the setting times are similar. The average difference of setting times between the GS free and the GS loaded granules was $24 \%$. Therefore, while the setting properties were determind by the volume of the setting agent and heat treatment temperature, the effect of GS loading on the setting was not significant.

An increase in setting times with an increase in the volume of setting agent was also observed for HA containing cements (H4T2 and H2T4), as shown in Fig. 7. To induce the proper setting of cement containing the HA granule, powdery $\beta$-TCP was added instead of granules as starting powder. The H4T2 consistently exhibited prolonged setting times compared to the H2T4 series, which is attributed the reduced reactivity of HA compared with $\beta$-TCP.

The temperature of the paste was recorded with time during the setting. As shown in Fig. 8, the temperature

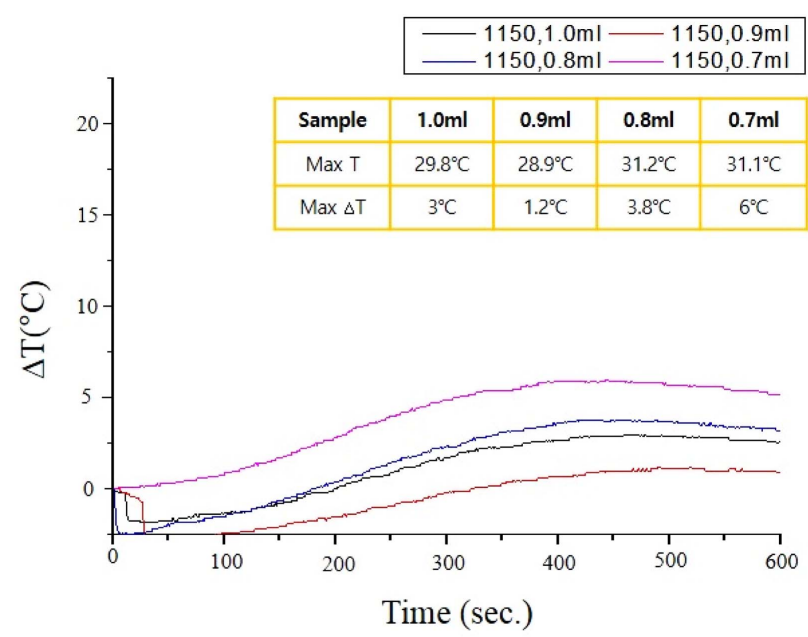

(b)

Fig. 9. Temperature increase during setting of cement (a) without GS and (b) with GS. 


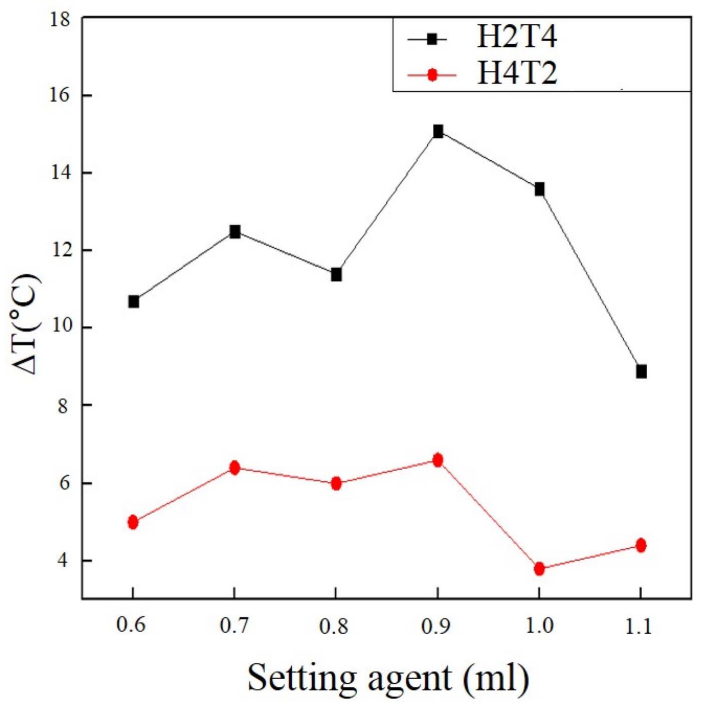

Fig. 10. Temperature increase during setting for H2T4 and H4T2 series with respect to the amount of setting agent.

increased rapidly and reached a peak at about five minutes. The temperature increase $(\Delta \mathrm{T})$ was dependent on the amount setting agent. As shown in Fig. $8, \Delta \mathrm{T}$ was as high as $19.6^{\circ} \mathrm{C}$ with $0.7 \mathrm{ml}$ of setting agent, but $\Delta \mathrm{T}$ decreased to $6.9^{\circ} \mathrm{C}$ with $1.0 \mathrm{ml}$ of setting agent. $\Delta \mathrm{Ts}$ were significantly reduced with $\beta$-TCP granules heated at $1150^{\circ} \mathrm{C}$. The $\Delta \mathrm{Ts}$ were less than $6.8^{\circ} \mathrm{C}$, regardless of the amount of setting agent (Fig. 9(a)). Loading of GS in the $\beta$-TCP granules resulted in the maximum $\Delta \mathrm{T}$ of $6.0^{\circ} \mathrm{C}$ (Fig. 9(b)). Thus, the loading of GS hardly affected the temperature increase of cement during setting.

The introduction of $\mathrm{HA}$ changed the $\Delta \mathrm{Ts}$ during the setting, as shown in Fig. 10. The maximum $\Delta$ Ts were 10 $14^{\circ} \mathrm{C}$ for $\mathrm{H} 2 \mathrm{~T} 4$. In comparison, the $\Delta \mathrm{T}$ decreased to less than

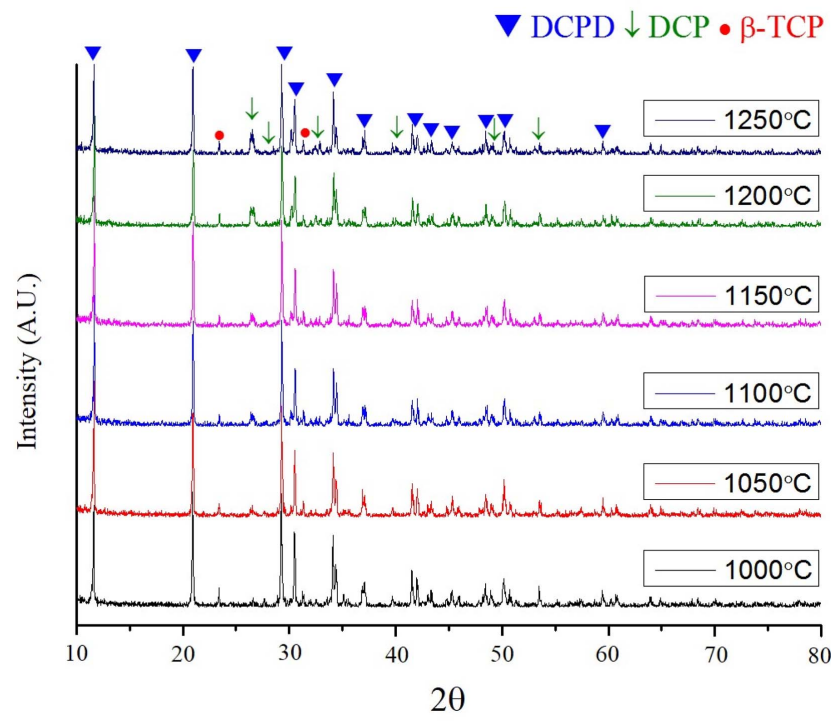

Fig. 11. X-ray diffraction patterns of the cement prepared with $1.0 \mathrm{ml}$ of setting agent and $\beta$-TCP granule heat treated at various temperatures.

$6^{\circ} \mathrm{C}$ for $\mathrm{H} 4 \mathrm{~T} 2$. The decrease in $\Delta \mathrm{T}$ is attributed to the increase in HA granules, since HA is less reactive than $\beta$ TCP. Despite the introduction of HA granules, the H4T2 exhibited similar $\Delta \mathrm{Ts}$ to those of the $\mathrm{T} 6$ heat treated granules at $1150^{\circ} \mathrm{C}$. Although $\mathrm{HA}$ granules reduced the $\Delta \mathrm{T}$, the powdery $\beta$-TCP in H4T2 offset the decrease in $\Delta \mathrm{T}$, unlike the T6 prepared with granular $\beta$-TCP.

\subsection{Phase analysis of cement after setting}

$\mathrm{X}$-ray diffraction (XRD) analysis revealed the primary end phase of cement as dicalcium phosphate dihydrate $\left(\mathrm{CaHPO}_{4} \cdot 2 \mathrm{H}_{2} \mathrm{O}\right.$ : DCPD). However, dicalcium phosphate

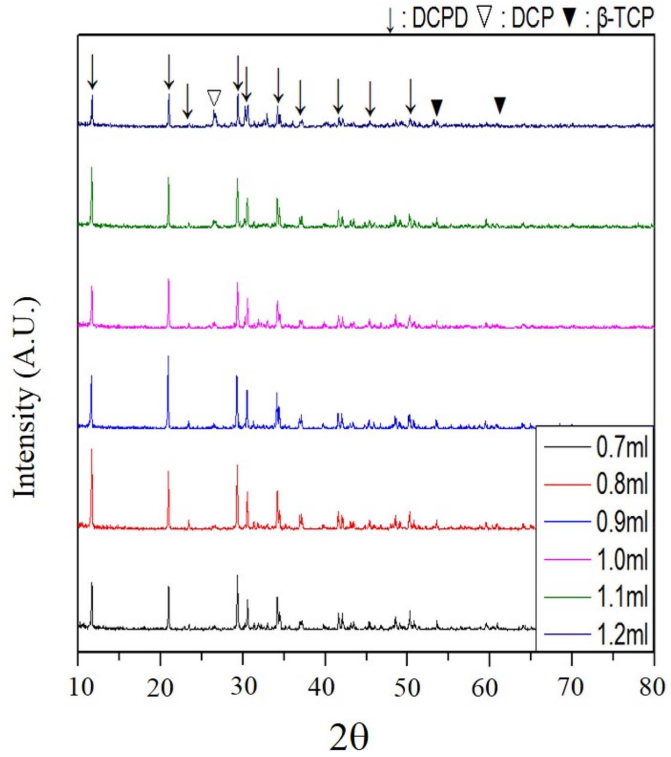

(a)

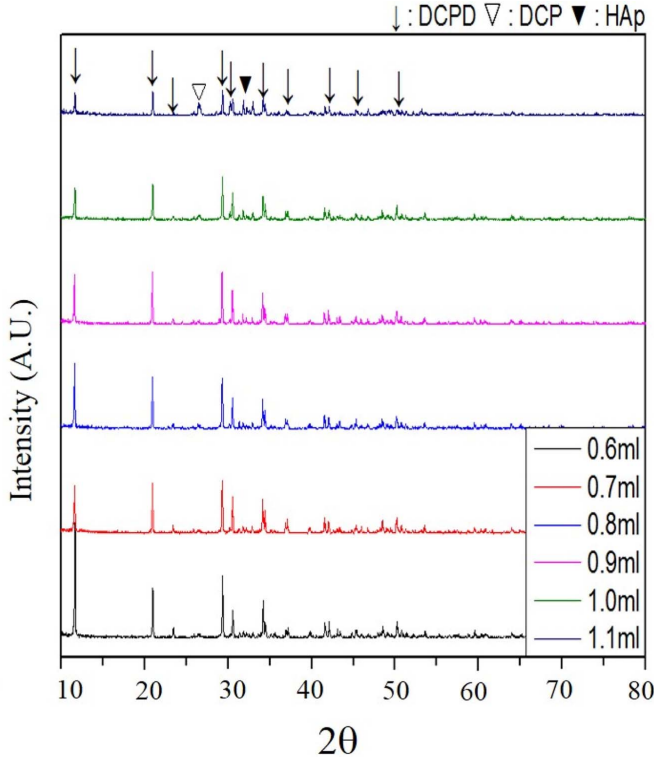

(b)

Fig. 12. X-ray diffraction patterns of the cement prepared from (a) H2T4 and (b) H4T2 with various setting agent amounts. 


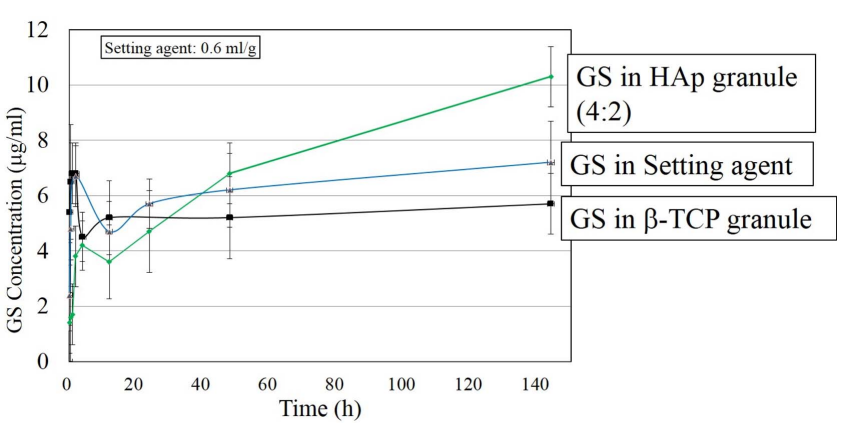

Fig. 13. The concentrations of GS released from cement specimens with time. GS in $\beta$-TCP granule, GS in setting agent, and GS in HA granule were tested.

$\left(\mathrm{CaHPO}_{4}\right.$ : DCP) was also found along with unreacted $\beta$ TCP, particularly from the paste in which the $\beta$-TCP granules were heated at elevated temperatures of $1250^{\circ} \mathrm{C}$ and with an excessive amount of setting agent of $1.0 \mathrm{ml}$ (Fig. 11). The primary peak $(2 \theta=30.188)$ of DCP $(\overline{1} 12)$ overlaps with the (221) of DCPD at 30.505, although secondary peaks at 26.426 and 26.586 are shown in Fig. 11.

XRD analysis from the H2T4 and H4T2 series also showed DCPD as the primary end phase (Fig. 12). However, DCP also appeared for both H2T4 and H4T2, particularly with an excessive setting agent. DCP was observed from the cements with $1.2 \mathrm{ml}$ in $\mathrm{H} 2 \mathrm{~T} 4$ and $1.1 \mathrm{ml}$ in H4T2.

\subsection{Release of GS from the cement}

Release of GS was compared with three selected specimens. As explained in the Materials and Methods section, the specimens were 'GS in setting agent', 'GS in $\beta$-TCP granule' and 'GS in HA granule'. Fig. 13 shows that the release behavior of the 'GS in HAp granule' specimen differ to that of the remaining specimens. In the cases of 'GS in Setting agent' and 'GS in $\beta$-TCP granule', the concentrations of GS increased rapidly in the early stage, and remained practically unchanged after $24 \mathrm{~h}$ and were then saturated at $6 \sim 7$ $\mu \mathrm{g} / \mathrm{ml}$. On the contrary, the concentration of 'GS in HAp

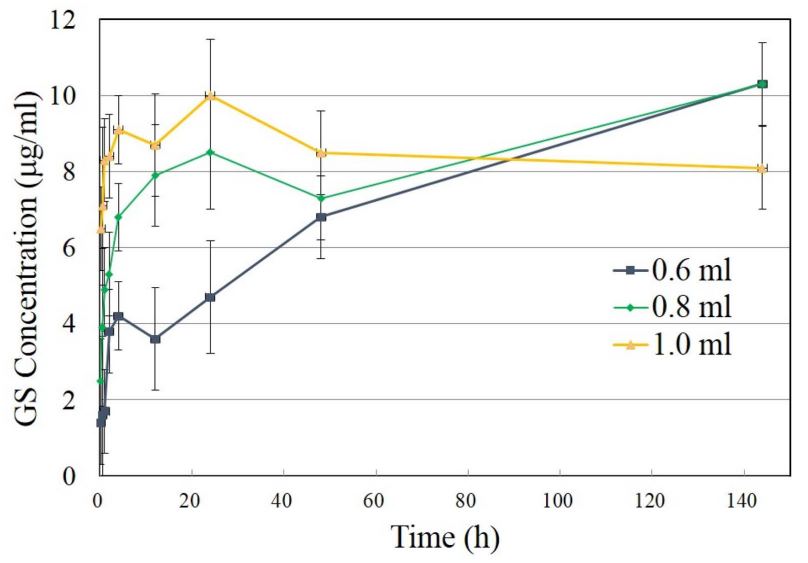

Fig. 14. The concentrations of GS released from H4T2 cement specimens with $0.6,0.8$ and $1.0 \mathrm{ml}$ of setting agent.

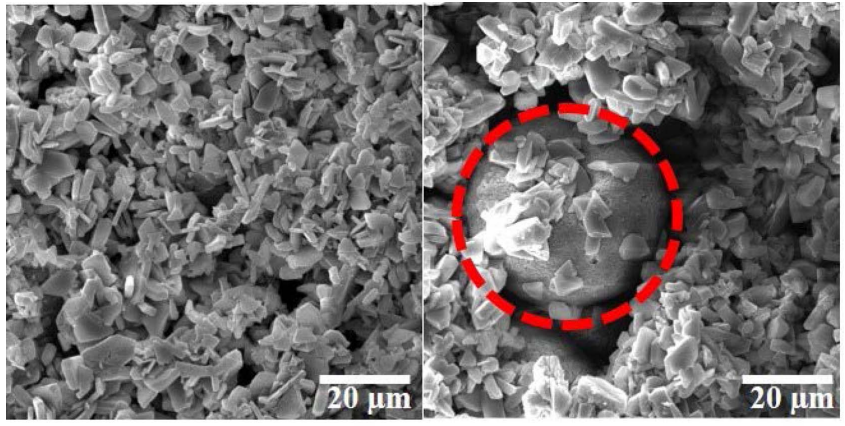

(a)

(b)

Fig. 15. Microstructure of cement prepared from (a) H2T4 and (b) H4T2 set with $0.6 \mathrm{ml}$ of setting agent.

granule' (H4T2) consistently increased to $10.3 \mu \mathrm{g} / \mathrm{ml}$ at 144 h. The result shown in Fig. 13 suggests that the use of HA granules as a carrier of antibiotics can be more helpful than $\beta$-TCP in the prolonged release of GS. This could be due to the chemical stability of HA compared to that of $\beta$-TCP.

As the H4T2 specimen showed an affirmative result, the investigation focused on H4T2 by varying the volume of the setting agent. Fig. 14 shows the concentrations of GS with time. The increase in the concentration of GS after $48 \mathrm{~h}$ was observed from the cement set with $0.8 \mathrm{ml}$ as well as from the cement set with $0.6 \mathrm{ml}$. From both specimens, the GS concentration reached $10.3 \mu \mathrm{g} / \mathrm{ml}$ at $144 \mathrm{~h}$. However, a cement set with $1.0 \mathrm{ml}$ showed a rapid initial increase in GS and the GS concentration did not increase after $24 \mathrm{~h}$. The results shown in Fig. 14 suggest that, while H4T2 has the capability of prolonged release when the cement is prepared with 0.6 or $0.8 \mathrm{ml}$ of setting agent, it is lost with the cement prepared with $1.0 \mathrm{ml}$ of setting agent.

\section{Discussion}

The results showed the importance of the HA in the prolonged release of the loaded antibiotics. As the granules were prepared to have a porous inner structure to hold the liquid drug, the exposure of the drug was minimized during the setting reaction. Thus, the setting properties such as setting time and temperature increase were marginally affected by the loading of the drug, as shown in Figs. 6 and 9. This result contrasts that of another study, in which the use of a setting agent dissolved with GS almost doubled the setting time due to the sulfate ion released from the GS. ${ }^{2)}$ Protection of GS within the dense granules was effective in blocking the influence of the GS on the setting reaction, as shown in this work. In addition, the temperature increase could be suppressed below $6^{\circ} \mathrm{C}$ by the heat-treatment to reduce the risk of affecting the loaded drug.

The brushite is generated from the setting reaction between $\beta$-TCP and MCPM, as shown in Eq. (1). MCPM first dissociates to produce phosphoric acid, as shown in Eq. (2). Therefore, $\beta$-TCP reacts with phosphoric acid to produce DCPD as presented in Eq. (1). 


$$
\begin{aligned}
& \mathrm{Ca}_{3}\left(\mathrm{PO}_{4}\right)_{2}+\mathrm{Ca}\left(\mathrm{H}_{2} \mathrm{PO}_{4}\right)_{2} \cdot \mathrm{H}_{2} \mathrm{O}+7 \mathrm{H}_{2} \mathrm{O} \rightarrow 4 \mathrm{CaHPO}_{4} \cdot 2 \mathrm{H}_{2} \mathrm{O} \text { (1) } \\
& \mathrm{Ca}\left(\mathrm{H}_{2} \mathrm{PO}_{4}\right)_{2} \cdot \mathrm{H}_{2} \mathrm{O} \rightarrow \mathrm{CaO}+2 \mathrm{H}_{3} \mathrm{PO}_{4}
\end{aligned}
$$

The reaction of granular $\beta$-TCP with phosphoric acid proceeds with the disintegration of granules and simultaneous release of the loaded drug. The rate of disintegration and consequent release depend on the reactivity of the granules. The heat-treatment of the granule at the elevated temperature reduces the surface area and the reactivity. However, the result shown in Fig. 13 suggests that the heat-treatment of the $\beta$-TCP granules did not sufficiently reduce the reactivity for a prolonged release. Instead, the introduction of HA successfully achieved the prolonged release of GS, as shown in Fig. 13. As the solubility of $\mathrm{HA}\left(\mathrm{K}_{\mathrm{s}}=10^{-116.8}\right)$ is significantly less than that of $\beta$-TCP $\left(\mathrm{K}_{\mathrm{s}}=10^{-28.9}\right)$ at $\left.25^{\circ} \mathrm{C},{ }^{14}\right)$ reduced disintegration is predicted. Fig. 15 shows the microstructures of the H2T4 and H4T2 cements set with $0.6 \mathrm{ml}$. The cement was composed of crystals, which are DCPD according to X-ray diffraction analysis, as shown in Fig. 12, with well developed habit planes. The habits of crystals suggest the growth of crystals during the setting reaction.

In $\mathrm{H} 4 \mathrm{~T} 2$, a trace of round granules (broken circle in the Fig. 15(b)) were observed surrounded by the DCPD crystals with the habit planes. The granules did not show habits, and the apparent size of the granules was approximately 40 $\mu \mathrm{m}$. As this size is slightly smaller than that of the HA granules initially introduced, the HA granules remained during the setting reaction and may have contributed to the release of the GS solution for a prolonged period.

The increase in the proportion of HA granules may be beneficial for the prolonged release of GS. However, it should be noted that the depletion of $\beta$-TCP can lead to failure in the setting reaction in Eqns. (1) and (2). Actually, the complete replacement of $\beta$-TCP with HA was not successful for the setting. The appropriate balance between $\beta$-TCP and HA requires further investigation. According to Fig. 13, the release of GS from H4T2 continued after $48 \mathrm{~h}$. The amount of GS released between 48 and $144 \mathrm{~h}$ was $3.8 \mu \mathrm{g} / \mathrm{ml}$. As the minimum inhibitory concentration of GS for staphylococcus is $4 \mu \mathrm{g} / \mathrm{ml},{ }^{18)}$ as little as $1 \mathrm{~cm}^{3}$ of the H4T2 cement with GS could almost suppress inflammation, even after $48 \mathrm{~h}$ of implantation.

Figures 11 and 12 show that the setting reaction with granules sometimes produced DCP along with DCPD. DCP is known to appear when a small driving force is provided for precipitation. ${ }^{13)}$ The formation of DCPD is the result of superior kinetics of growth when precipitation of both DCPD and DCP is allowed. ${ }^{19)}$ In contrast, the DCP dominates with the selective formation ${ }^{19)}$ of DCP, as its kinetics of growth is inferior. The magnitude of driving force may depend on supersaturation during setting. Figs. 11 and 12 show that DCP appeared with an excessive setting agent, which dilutes the concentration of phosphoric acid. DCP also appeared with $\beta$-TCP heat treated at an elevated temperature, at which the reactivity is reduced. The HA granules have a similar effect, as their solubility is reduced compared with $\beta$-TCP. Thus, the introduction of HA can also lead to the formation of DCP as a result of diluted supersaturation.

The formation of DCP can also affect the release of GS. It should be noted that the formation of DCP results in increased porosity ${ }^{13)}$ and consequent reduction of strenth. ${ }^{19)}$ The release of the loaded drug should be enhanced under an increased porosity. According to Fig. 14, H4T2 with $0.8 \mathrm{ml}$ of setting agent released more GS than $\mathrm{H} 4 \mathrm{~T} 2$ with $0.6 \mathrm{ml}$ of setting agent during the initial moment, which can also be attributed to the increased porosity of H4T2 with $0.8 \mathrm{ml}$ of setting agent. The initial accelerated release of H4T2 with $1.0 \mathrm{ml}$ shown in Fig. 14 can be the result of both increased porosity and the formation of DCP as shown in Fig. 12 .

According to Fig. 13, the concentration of GS from H4T2 reached $10.3 \mu \mathrm{g} / \mathrm{ml}$ at $144 \mathrm{~h}$. As the aliquot was taken from the $250 \mathrm{ml}$ batch, the amount of GS in the solution was 2.5 $\mathrm{mg}$. The GS in the cement was derived from the $0.4 \mathrm{~g}$ of HA. As the HA granules contained $0.89 \mathrm{ml} / \mathrm{g}$ of $\mathrm{GS}$, the total amount of GS in $1 \mathrm{~g}$ of cement was $17.8 \mathrm{mg}$, considering the density $(50 \mathrm{mg} / \mathrm{ml})$ of GS solution. Therefore, $14.4 \%$ of GS was released from the cement up to $144 \mathrm{~h}$. This suggests that the GS remains in the cement. According to a previous report, ${ }^{2)}$ GS was completely released after $100 \mathrm{~h}$, when the GS was dissolved in the setting agent of brushite cement. This shows that use of dense granules as a vehicle for loading antibiotics is an effective method to extend the release of GS.

\section{Conclusions}

Brushite bone cement was prepared using granulated $\beta$ TCP and HA as a vehicle to load antibiotics. By infiltrating the GS solution within the interconnected pores of the granule, the antibiotics were separated from the acid emitted during the setting reaction of cement. The setting time and temperature change were therefore unaffected by the loading of GS. The cement containing $0.4 \mathrm{~g}$ of HA and $0.2 \mathrm{~g}$ of $\beta$ TCP (H4T2) set with 0.6 and $0.8 \mathrm{ml}$ of setting agent, respectively, showed the best results. The concentration of GS reached $10.3 \mu \mathrm{g} / \mathrm{ml}$ at $144 \mathrm{~h}$ after setting and even the amount of released GS after $48 \mathrm{~h}$ was close to $4 \mu \mathrm{g} / \mathrm{ml}$, which is the minimum inhibitory concentration of GS for staphylococcus. Thus, the H4T2 cement might be effective in the suppression of inflammation after surgery for a sufficient period. The prolonged release behavior was only observed in the cement with HA granules. As the HA granules were found to disintegrate at a slow rate due to the reduced chemical reactivity compared with $\beta$-TCP, the release of GS contained in the granule should be prolonged.

\section{Acknowledgments}

This work was supported by a grant from 2016 Research Funds of Andong National University. 


\section{REFERENCES}

1. M. Bohner, "Calcium Orthophosphates in Medicine: from Ceramics to Calcium Phosphate Cements," Injury, 31 [S4] D37-47 (2000).

2. M. Bohner, J. Lemaitre, P. Van Landuyt, P. Y. Zambelli, H. P. Merkle, and B. Gander, "Gentamicin-Loaded Hydraulic Calcium Phosphate Bone Cement as Antibiotic Delivery System," J. Pharm. Sci., 86 [5] 565-72 (1997).

3. K. Hartke, H. Hartke, E. Mutschler, G. Rücker, and M. Wichtl, "Gentamicinsulfat (Kommentar)," pp. G11-1-G116 in Deutsches Arzneibuch 10 Kommentar für Studierende, Govi-Verlag, Fankfort, 1991.

4. J. Randzio, K. Thoma, R. Alex, and B. Rhomberg, "Healing and Pharmacokinetics of a Beta-Tricalcium PhosphateGentamycin Combination in Animal Studies (Preliminary Report)," Dtsch. Zahnärztl. Z., 40 [6] 668-71 (1985).

5. F. Theiss, D. Apelt, B. Brand, A. Kutter, K. Zlinksky, M. Bohner, S. Matter, C. Frei, J. A. Auer, and B. von Rechenber, "Biocompatibility and Resorption of a Brushite Calcium Phosphate Cement," Biomaterials, 26 [21] 4383-94 (2005).

6. Walenkamp GHIM, Gentamicin-PMMA Beads; pp. 50-7, Ed. by Merck, Merck, Darmstadt, 1983.

7. M. Bohner, J. Lemaitre, H. P. Merkle, and B. Gander, "Control of Gentamicin Release from a Calcium Phosphate Cement by Admixed Poly(Acrylic Acid)," J. Pharm. Sci., 89 [10] 1262-70 (2000).

8. K. S. Oh, H. W. Choi, and S. R. Kim, "Temperature Rise and Setting of $\beta$-TCP-MCPM Bone Cement Containing Dense $\beta$-TCP Granules," Curr. Appl. Phys., 5 [5] 489-92 (2005).

9. A. A. Mirtchi, J. Lemaitre, and N. Terao, "Calcium Phosphate Cements: Study of the $\beta$-Tricalicum Phosphate-Monocalcium Phosphate System," Biomaterials, 10 [7] 475-80 (1989).
10. K. Ohura, M. Bohner, P. Hardouin, J. Lemaitre, G. Pasquier, and B. Flautre, "Resorption of, and Bone Formation from, New $\beta$-Tricalcium Phosphate-Monocalcium Phosphate Cements: An in vivo Study," J. Biomed. Mater. Res. 30 [2] 193-200 (1996).

11. K. S. Oh, S. R. Kim, and P. Boch, "Synthesis and Properties of Bone Cement Containing Dense $\beta$-TCP Granules," Key Eng. Mater. 254-256 237-40 (2004).

12. K. S. Oh, and S. R. Kim, "Effect of the Composition in $\beta$ TCP MCPM Bone Cement Containing Dense $\beta$-TCP Granules," Key Eng. Mater., 284-286 141-44 (2005).

13. S. A. Lee, T. J. Chung, and K. S. Oh, "Effect of Storage Conditions on the Setting Properties of Brushite Bone Cement Containing Granular $\beta$-Tricalcium Phosphate," $J$. Korean Ceram. Soc., 45 [10] 624-29 (2008).

14. S. V. Dorozhkin, Calcium Orthophosphates: Applications in Nature, Biology, and Medicine; p. 850, Pan Stanford, Singapore, 2012.

15. S. M. Seo, D. M. Kim, T. J. Chung, J. J. Yoo, H. J. Kim, H. J. Chun, J. W. Jang, and K. S. Oh, "Effect of Milling time on the Viscosity of Hydroxyapatite Suspension," Curr. Appl. Phys. 12 [S2] S71-5 (2012).

16. G. Bertrand, P. Roy, C. Filiatre, and C. Coddet, "SprayDried Ceramic Powders: A Quantitative Correlation between Slurry Characteristics and Shapes of the Granules," Chem. Eng. Sci., 60 [1] 95-102 (2005).

17. B. E. Rosenkrantz, J. R. Greco, J. G. Hoogerheide, and E. M. Oden, "Gentamicin Sulfate," pp. 295-340 in Analytical Profiles of Drug Substances, Vol 9, Ed. by K. Florey, Academic Press, New York, 1981.

18. J. Morant and H. Ruppaner, Arzneimittelkompendium der Schweiz; p. 834, Basler Zeitung, Basel, 1996.

19. U. Gbureck, S. Dembski, R. Thull, and J. E. Barralet, "Factors Influencing Calcium Phosphate Cement ShelfLife," Biomaterials, 26 [17] 3691-97 (2005). 